\title{
KURZBESPRECHUNGEN
}

\author{
Frank J. Sorauf
}

\section{Party Politics in America}

Fourth Edition, Little, Brown and Company, Boston, Toronto, 1980, 436 S.

Dieses Buch entwickelt nicht den Idealtypus des USA-Parteiwesens, wie ihn die Verfassung voraussetzt, und mißt nicht die Wirklichkeit daran, ob sie diesen Verfassungserwartungen entspricht. Der Verf. schildert vielmehr ausschließlich und in bis ins letzte gehender Detailliertheit dasjenige, was ist, wozu er vor allem das Nachlassen der Virulenz dieser Parteien rechnet: ,But for the moment, at least, it does not look as though the parties will disappear“" (S. 420) ${ }^{1}$. Doch enthält das Buch auch konkrete Beobachtungen von allgemeiner Bedeutung. Hierher gehört die immer wieder getroffene Feststellung, daß die primaries die Parteien an einer Personalplanung hindern, die ihnen zu Fachleuten auf allen wesentlichen Gebieten verhilft; vor allem ihnen aber auch Personen aufdrängen, die mangels Verbundenheit mit der Partei nicht bereit sind, Disziplin zu wahren. Vor allem aber zëigt die Darstellung immer wieder, daß die Parteien auch heute noch weit davon entfernt sind, sich zu gesamtnationalen Gebilden integriert und organisiert zu haben, daß sie vielmehr im Zustand von mehr oder weniger lockeren Bündnissen verblieben sind, die nur bei einer Gelegenheit, nämlich bei der Aufstellung des Präsidentschaftskandidaten, als Einheit hervortreten.

Herbert Krüger

\section{E. Digby Baltzell}

\section{Puritan Boston and Quaker Philadelphia}

The Free Press New York 1979, XII, 585 S., \$ 19.95

Der Verf. hat seine Arbeit der These gewidmet, daß zwischen einer Führenden Schicht oder Herrschenden Klasse einerseits und einer Elite andererseits zu unterscheiden sei (S. 24 ff.): Eine Führende Schicht ist für ihn eine vor allem auch durch connubium verflochtene Gesamtheit von etwa 50 Familien; eine Elite dagegen ist lediglich eine Summe von einzelnen führenden Persönlichkeiten. Der Verf. gibt der ersten Alternative den Vorzug, weil die Mitglieder einer Führenden Schicht sich traditionell und konventionell dafür verantwortlich fühlen, den Gemeinwesen ehrenamtliche Amtsträger zu stellen und sie zu finanzieren (Universitäten!), während eine Elite sich zu alledem nicht veranlaßt fühlt. Diese Alternative wird veranschaulicht und belegt durch eine Gesellschafts- und Familiengeschichte von Boston (Mass.) und Philadelphia (obwohl es hier wenigstens teil- und zeitweise eine Führende Schicht gegeben hat; vgl. S. 450). Angesichts der Unmenge an Detail, das der Verf. vorführt, nimmt es nicht wunder, daß die These immer wieder außer Sicht gerät. Aber auch als bloße Erzählung bleibt das Buch unterrichtend und lehrreich vor allem insofern es Biographien derjenigen Personen liefert, die die USA groß gemacht haben. Ertragreich und wichtig scheinen mir insbesondere zu sein die Ausführungen S. 110, 166 ff., 265, 283, 319, 337, 380, 455 f.: Quäkerisches Denken ist heute in USA einflußreicher als jemals zuvor.

Herbert Krüger

1 vgl. hierzu auch soeben William J. Crotty-Gary C. Jacobson, American Parties in Decline, im gleichen Verlage, 1980. 